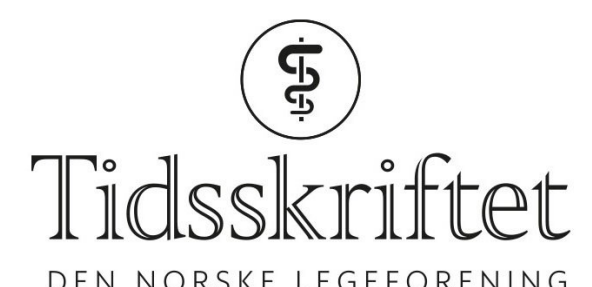

DEN NORSKE LEGEFORENING

\title{
Generisk bytte av legemidler i sykehus
}

ORIGINALARTIKKEL

\section{ROLF JOHANSEN}

E-post: rolf.johansen@sykehusapotekene.no Sykehusapoteket Lillehammer

Sykehusapotekene HF

Han har bidratt med utforming av problemstilling, datainnsamling, analyse og tolkning av data, utarbeiding og revisjon av manus.

Rolf Johansen er cand.pharm. og pensjonert sykehusfarmasøyt.

Forfatter har fylt ut ICMJE-skjemaet og oppgir ingen interessekonflikter.

\section{YVONNE ANDERSSON}

Sykehusapotekene HF hovedkontor

Sykehusapotekene HF

Hun har bidratt med analyse og tolkning av data og revisjon av manus.

Yvonne Andersson er ph.d. og forsknings- og utviklingssjef.

Forfatter har fylt ut ICMJE-skjemaet og oppgir ingen interessekonflikter.

\section{BAKGRUNN}

Det er ofte behov for at sykepleiere foretar generisk bytte av legemidler i sykehus.

Sykepleiere kan etter gjeldende forskrifter kun foreta slikt bytte med utgangspunkt i legemiddelverkets bytteliste eller lokal bytteliste i sykehusets kvalitetssystem.

\section{MATERIALE OG METODE}

6 oo sykepleiere ved 23 kirurgiske og 28 medisinske sengeposter i tre helseforetak ble invitert til en nettbasert spørreundersøkelse om generisk bytte av legemidler i sykehus. Studien ble gjennomført for å vurdere hvordan dagens praksis fungerer med hensyn til risikofaktorer, dokumentasjon og eventuelle forbedringsmuligheter.

\section{RESULTATER}

Svarandelen i undersøkelsen var $52 \% .57 \%$ av sykepleiere utførte generisk bytte av legemidler daglig, mens $8 \%$ overlot til lege å bestemme bytter like ofte. Av seks tenkte eksempler på generisk bytte svarte sykepleierne i median feil på to, lokal bytteliste ble brukt som eneste kilde til informasjon i $23 \%$ av tilfellene og ingen brukte legemiddelverkets bytteliste på nett. $37 \%$ svarte at generisk bytte ble dokumentert $\mathrm{i} \geq 8 \mathrm{o} \% \mathrm{av}$ tilfellene, mens $18 \%$ svarte at dobbeltkontroll ble utført $\mathrm{i} \geq 8 \mathrm{o} \%$ av tilfellene. 
Generisk bytte i sykehus gir store muligheter for feil. Sikkerhet og dokumentasjon ved generisk bytte bør primært ivaretas av datatekniske løsninger gjennom innføring av elektronisk medisinkurve. Alternativt bør godkjent bytteliste være eneste kilde for bytte.

Med generisk bytte menes bytte mellom preparater med forskjellig navn, men som har samme virkestoff og virkning. I 2017 utgjorde generika 50 \% av legemiddelmarkedet, målt i definerte døgndoser (1). I sykehus er en stor del av legemiddelinnkjøpene satt ut på anbud. For siste 12 måneder, per 1.8.2018, var $86 \%$ av legemiddelkostnadene gjennom leverandøravtaler, totalt 9507 millioner kroner, med en gjennomsnittlig rabatt på $40 \%$ (2). I praksis må man i sykehus bytte til de legemidlene avdelingen har på lager eller helseforetaket har innkjøpsavtale på.

Ordinering av legemidler er et legeansvar, men ofte er det sykepleiere som møter utfordringen med bytte i forbindelse med istandgjøring av legemidlene. Sykepleieres adgang til generisk bytte er regulert i forskrift av 2008 (3). En viktig forutsetning for at sykepleiere skal kunne bytte er at sykehuset har et kvalitetssystem som sikrer forsvarlige rutiner, og at preparatene er godkjent byttbare. Legemiddelverket vurderer hvilke legemidler som er godkjent byttbare bl.a. på grunnlag av bioekvivalensstudier (4). Etter 2012 har søk på godkjent byttbare preparater vært mulig på Legemiddelverkets hjemmeside og nettutgaven av Felleskatalogen.

Anatomisk-terapeutisk-kjemisk system (ATC-systemet) er et hierarkisk klassifikasjonssystem for legemidler, med grupper på fem nivåer (5). ATC-registeret finnes også i Felleskatalogen og er egnet til å finne beslektede legemidler, men angir ikke hvilke som er godkjent som byttbare.

Hvis ikke byttelisten følges, vil generisk bytte i sykehus medføre en rekke risikofaktorer, for eksempel at man forbytter legemiddelform eller styrke $(6,7)$. I denne studien $ø$ nsket vi å undersøke hvordan dagens praksis fungerer med tanke på risikofaktorer, ressursbruk og etterlevelse av forskrifter, for å avdekke eventuelle forbedringsmuligheter.

\section{Materiale og metode}

Korrespondanse med personvernombud avklarte at studien ikke var meldepliktig. Den inneholdt ingen pasientdata og krevde derfor ikke godkjenning fra Regional etisk komité.

Studien ble gjennomført som en nettbasert personliggjort spørreundersøkelse med programvaren Questback EFS 10.9 (8) blant sykepleiere på medisinske og kirurgiske sengeposter i november/desember 2016. Personer med annen hovedarbeidsplass enn medisinsk eller kirurgisk sengepost ble ekskludert fra studien.

Respondenter ble hentet fra 23 kirurgiske og 28 medisinske sengeposter ved tre forskjellige helseforetak i Helse Sør-Øst. Sykehusenes prosedyrer ble skaffet gjennom lokalt sykehusapotek og viste at alle hadde rutiner der sykepleier manuelt gjorde i stand legemiddeldoser til den enkelte pasient ut fra medisinkurve, at sykepleier kunne utføre generisk bytte basert på bytteliste og at dette skulle dokumenteres i medisinkurven. Helseforetakene hadde hver sin lokale bytteliste. Ingen av sykehusene i studien brukte maskinell pakking av medisindoser til den enkelte sykehuspasient og ingen var universitetssykehus.

Sykehusene brukte datasystemet Tønsys til bestillinger fra sykehusapotek (9). Liste i Tønsys med sykepleiere på aktuelle avdelinger ble gruppert ut fra helseforetak og medisinsk eller kirurgisk sengepost. Disse seks gruppene ble sortert etter sykehuspost og deretter alfabetisk etter navn på sykepleier. Herfra ble det trukket 1oo personer fra hver gruppe ved systematisk tilfeldig utvalg (10). Kontaktopplysningene ble kontrollert mot Personalportalen (Sykehuspartner). 
Spørreskjemaet besto av 17 spørsmål med faste svaralternativer og tvungne svar samt 16 spørsmål med åpne svar, hvorav 12 var tvungne (appendiks).

Forskriften krever at dobbeltkontroll må dokumenteres for å være gyldig (3). For å unngå at respondentene tok med tilfeller der to kontrollerte uten å dokumentere, ble det $\mathrm{i}$ spørreskjemaet spurt etter «dobbeltkontroller som begge kvitterer for». Sykepleierne ble bedt om å ta stilling til seks tenkte eksempler på generisk bytte. Her ble de anbefalt å ha tilgang på samme hjelpemidler som i en vanlig arbeidssituasjon og løse oppgavene mest mulig likt en reell situasjon. En pilotstudie ble gjort med syv sykepleiere for å optimalisere spørreskjemaet.

Data ble overført og bearbeidet i Microsoft Excel 2013.

\section{Resultater}

$313 / 600(52 \%)$ av de forespurte sykepleierne fullførte spørreskjemaet. Ni av disse ble ekskludert fra materialet, slik at totalt 304 sykepleiere ble inkludert i videre analyser. 159/304 (52\%) hadde kirurgisk sengepost og 145/304 (48 \%) medisinsk sengepost som hovedarbeidsplass. For helseforetak 1, 2 og 3 var andelene henholdsvis 103/304 (34\%), 84/304 (28\%) og 117/304 (38\%). Median alder var 38 år (variasjonsbredde 22-67) og median arbeidstid i sykehus var 9 år (variasjonsbredde 0,5-45). 100/304 (33\%) av sykepleierne arbeidet i full stilling og 290/304 (95\%) var fast ansatt.

Studien viste at 174/304 av sykepleierne (57\%) gjorde generiske bytter minst én gang daglig, mens 23/304 (8\%) overlot til legen å bestemme medikamentbytter like ofte (figur 1).

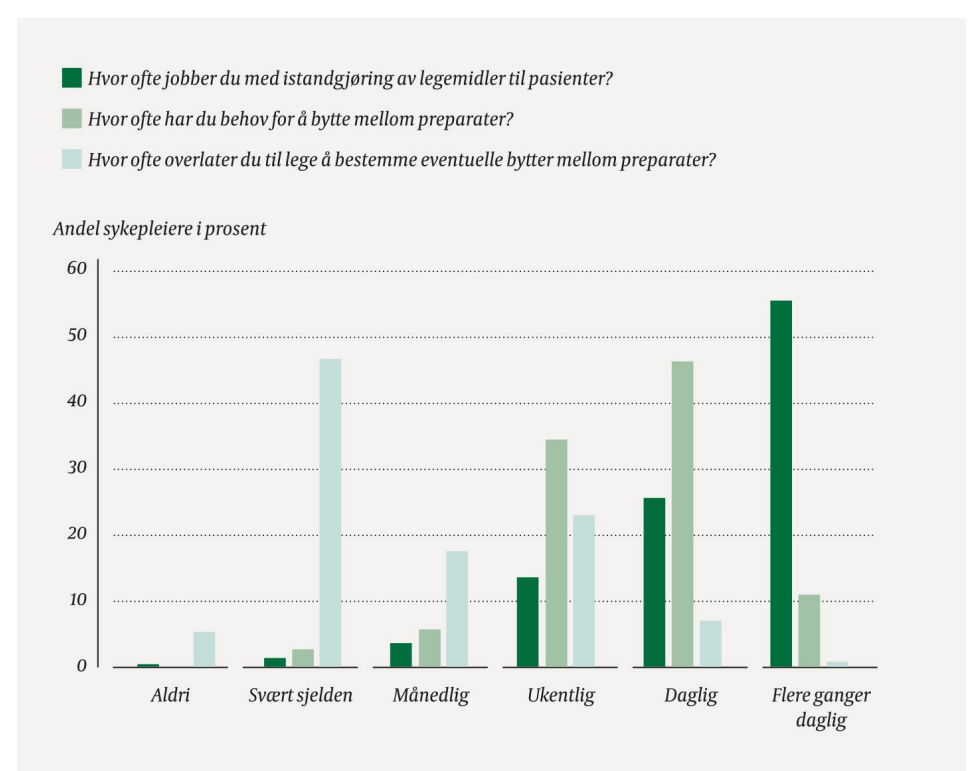

Figur 1 Sykepleieres angivelse av hvor ofte de henholdsvis jobbet med istandgjøring av legemidler, hadde behov for å bytte mellom preparater og overlot til lege å bestemme bytter. Spørsmålene hadde tvungne svar og seks svaralternativer $(n=304)$.

På et åpent spørsmål med tvunget svar ( $\mathrm{n}=304)$ oppga sykepleierne at generisk bytte ga dem merarbeid på i median 7 minutter (variasjonsbredde o-40 minutter).

DOKUMENTASJON OG DOBBELTKONTROLL

113/304 sykepleiere (37\%) oppga at generisk bytte ble dokumentert $\mathrm{i} \geq 80 \%$ av tilfellene, mens 55/304 (18\%) svarte at det ble gjennomført dobbeltkontroll på generisk bytte $\geq 80 \%$ av tilfellene (figur 2). 


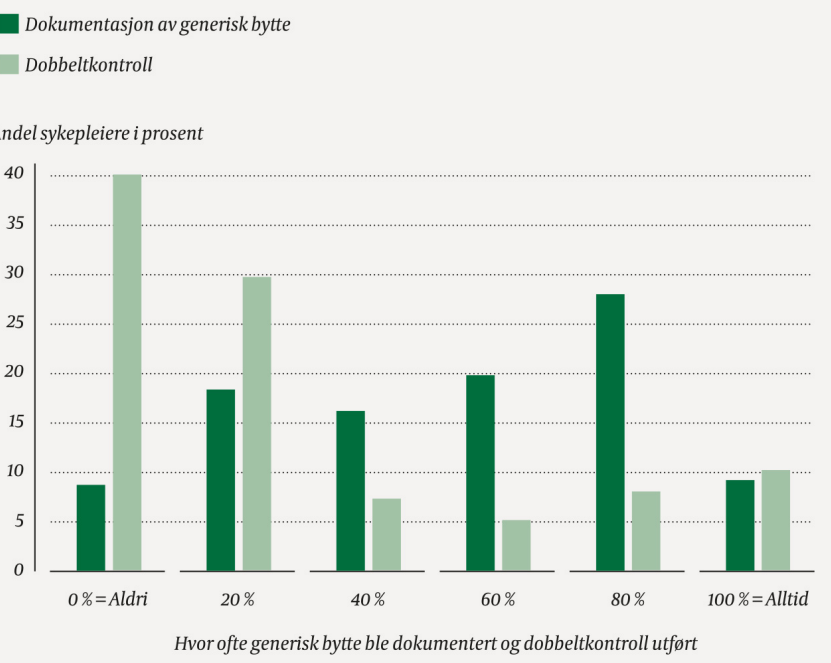

Figur 2 Sykepleieres angivelse av hvor ofte generisk bytte ble dokumentert og hvor ofte det ble utført dobbeltkontroll på generisk bytte. Spørsmålet hadde tvunget svar og seks svaralternativer $(n=304)$.

For hvert av de tre helseforetakene var andelen som oppga $\geq 80 \%$ dokumentasjon av generisk bytte henholdsvis 48/103 (47\%), 14/84 (17\%) og 51/117 (44\%). Fordelt på avdelingstype for alle helseforetak, var tilsvarende tall 6o/159 (38\%) for kirurgiske og 53/145 (37\%) for medisinske. Andel som oppga $\geq 80 \%$ dobbeltkontroll på generisk bytte var henholdsvis 18/103 (17\%), 9/84 (11\%) og 28/117 (24\%) for helseforetak 1, 2 og 3, mens andelen var 34/159 (21\%) for kirurgiske sengeposter og 21/145 (14\%) for medisinske sengeposter.

\section{INFORMASJONSKILDER}

Opplysninger om hvilke informasjonskilder som ble brukt ved generisk bytte var hentet fra tre ulike spørsmål som alle hadde tvungne svar.

På et åpent spørsmål om hvordan de gikk frem for å se om preparater kunne byttes, nevnte $187 / 304$ (62 \%) konkret bruk av ATC-registeret. 2/304 (1\%) nevnte at sykehusets bytteliste var eneste godkjente kilde, og 11/304 (4\%) at de sjekket om preparatene hadde samme legemiddelform.

274/304 (90\%) svarte Felleskatalogen og 212/304 (70\%) sykehusets lokale bytteliste på et åpent spørsmål om hvilke informasjonskilder som ble brukt ved generisk bytte (flere kilder kunne oppgis). I tillegg oppga 37/304 (12 \%) apotek eller farmasøyt, 36/304 (12\%) andre sykepleiere/kolleger, 33/304 (11\%) leger og 18/304 (6\%) diverse andre kilder.

De 304 sykepleierne svarte for hvert av de seks eksemplene på et åpent spørsmål med tvunget svar om hva de brukte som informasjonskilde ved dette konkrete byttet, og kunne samtidig frivillig gi tilleggsopplysninger om hvilke vurderinger de gjorde ved byttet, til sammen 1824 fritekstkommentarer (304 x 6).146/1 824 (8\%) oppga mer enn én informasjonskilde, mens informasjonskilde ikke fremgikk i 208 (11\%) av besvarelsene. ATCregisteret ble oppgitt som informasjonskilde i $282 / 1824$ kommentarer (15\%), mens 857 (47\%) oppga Felleskatalogen uten å nevne ATC-registeret spesifikt. 546 (30\%) oppga bytteliste som kilde, hvorav bytteliste var eneste kilde hos 411 (23\%).

Fordelt på det enkelte helseforetak var andelen kommentarer med bytteliste som eneste kilde henholdsvis 250/618 (40 \%) for helseforetak 1, 75/504 (15\%) for helseforetak 2 og 86/702 (12\%) for helseforetak 3 . Andre svar utgjør til sammen 82/1 824 (4\%). Oversikt over byttbare preparater på Legemiddelverkets hjemmeside og lenken til «byttegruppe» under preparatomtaler i nettutgaven av Felleskatalogen ble ikke nevnt av noen sykepleiere ved noen spørsmål. 
I seks tenkte eksempler på generisk bytte hadde sykepleierne feil svar på i median to spørsmål (variasjonsbredde o-5) (tabell 1). 48/304 (16\%) svarte riktig på alle seks eksemplene. Ingen svarte feil på alle seks, men 108/304 (36\%) svarte feil på tre eller flere eksempler.

\section{Tabell 1}

Svarandel i prosent for sykepleiernes vurderinger av seks eksempler på generisk bytte. Feil svar (basert på Legemiddelverkets bytteliste) er markert med understreking. Spørsmålene hadde tvungne svar og tre svaralternativer $(n=304)$.

\begin{tabular}{|c|c|c|c|c|}
\hline Ville du byttet: & $\begin{array}{c}\text { Jeg } \\
\text { ville } \\
\text { ha } \\
\text { byttet } \\
\text { disse } \\
(\%)\end{array}$ & $\begin{array}{c}\text { Jeg } \\
\text { ville } \\
\text { ikke } \\
\text { ha } \\
\text { byttet } \\
\text { disse } \\
(\%)\end{array}$ & $\begin{array}{c}\text { Jeg } \\
\text { finner } \\
\text { ikke ut } \\
\text { om } \\
\text { disse } \\
\text { kan } \\
\text { byttes } \\
(\%) \\
\end{array}$ & Hovedforskjell mellom preparatene \\
\hline $\begin{array}{l}\text { Plavix } 75 \mathrm{mg} \\
\text { tabletter } \\
\text { med } \\
\text { Clopidogrel } 75 \mathrm{mg} \\
\text { tabletter? }\end{array}$ & 92 & 6 & 2 & Godkjent byttbare av Legemiddelverket \\
\hline $\begin{array}{l}\text { Ery-Max } 250 \mathrm{mg} 2 \\
\text { stk kapsler } \\
\text { med } \\
\text { Abboticin ES } \\
500 \mathrm{mg} 1 \mathrm{stk} \\
\text { tablett? }\end{array}$ & 57 & 33 & 10 & $\begin{array}{l}\text { Ulik biologisk tilgjengelighet, } 250 \mathrm{mg} \text { Ery- } \\
\text { max kapsler tilsvarer } 500 \mathrm{mg} \text { Abboticin ES } \\
\text { tabletter }\end{array}$ \\
\hline $\begin{array}{l}\text { Sinemet 25/100 } \\
\text { tabletter } \\
\text { med } \\
\text { Madopar 25/100 } \\
\text { kapsler? }\end{array}$ & 33 & 52 & 15 & $\begin{array}{l}\text { Kombinasjonspreparater med levodopa } \\
\text { der dopadekarboksylase-hemmeren er } \\
\text { forskjellig }\end{array}$ \\
\hline $\begin{array}{l}\text { Tramagetic OD } \\
200 \mathrm{mg} \\
\text { depottabletter } \\
\text { med } \\
\text { Nobligan Retard } \\
200 \mathrm{mg} \\
\text { depottabletter? }\end{array}$ & 61 & 33 & 6 & $\begin{array}{l}\text { Depotpreparater med samme virkestoff, } \\
\text { der anbefalt doseringsintervall er } 24 \text { timer } \\
\text { for den ene og } 12 \text { timer for den andre }\end{array}$ \\
\hline $\begin{array}{l}\text { Zestoretic mite } \\
\text { tabletter } \\
\text { med } \\
\text { Lisinopril } 10 \mathrm{mg} \\
\text { tabletter? }\end{array}$ & 21 & 74 & 5 & $\begin{array}{l}\text { Zestoretic mite er kombinasjons-preparat } \\
\text { med hydroklortiazid i tillegg til lisinopril }\end{array}$ \\
\hline $\begin{array}{l}\text { Oxycodone kapsler } \\
20 \mathrm{mg} \\
\text { med } \\
\text { OxyContin } \\
\text { depottabletter } \\
20 \mathrm{mg} \text { ? }\end{array}$ & 23 & 72 & 5 & $\begin{array}{l}\text { Oxycodone er hurtigvirkende kapsler, } \\
\text { mens OxyContin er et depotpreparat }\end{array}$ \\
\hline
\end{tabular}

Henholdsvis 174/304 (57\%) og 184/304 (61\%) svarte feil på eksemplene med Ery-Max kapsler/Abboticin ES tabletter og Tramagetic OD/Nobligan Retard. I de tre andre eksemplene som ikke var byttbare, var andel feil 65/304 (21\%) for Zestoretic mite/Lisinopril tabletter, 71/304 (23\%) for Oxycodone kapsler/OxyContin depotabletter og 99/304 (33\%) for Sinemet tabletter/Madopar kapsler. 19/304 (6\%) svarte feil på det ene eksemplet med godkjente byttbare preparater (Plavix/Clopidogrel tabletter).

Av de 1824 kommentarene om informasjonskilder i de seks tenkte eksemplene på generisk 
bytte var det 411 svar der lokal bytteliste var eneste kilde. Der lokal bytteliste ble angitt brukt som eneste kilde, svarte 284/411 (69\%) rett, 86/411 (21\%) feil og 41/411 (10 \%) «vet ikke».

108/1 824(6\%) kommentarer om hvordan sykepleierne vurderte byttbarheten viste korrekt svar på bytte samtidig som det ble brukt feil begrunnelse, for eksempel at man ikke ville bytte Madopar og Sinemet fordi den ene var kapsel og den andre tablett. 182/1 824 av svarene (10\%) hadde tilleggskommentar om at de i en reell situasjon ville konferert med legen.

231/304 (76\%) av respondentene hadde tilgang til samme informasjonskilder som i en vanlig jobbsituasjon når de svarte på spørreskjemaet, mens 54/304 (18\%) hadde delvis tilgang. På et åpent frivillig spørsmål svarte $56 / 65$ sykepleiere at de generelt ville sjekket byttbarheten bedre i en jobbsituasjon, f.eks. ved å bruke mer tid eller spørre kolleger.

\section{Diskusjon}

Dokumentasjonen av generisk bytte var mangelfull i alle de tre helseforetakene. Manglende dokumentasjon av generisk bytte i pasientens medisinkurve er et brudd på forskriften (3). Ved mangelfull dokumentasjon blir det umulig for legen å vurdere byttene, og eventuelle feil kan vanskelig oppdages i ettertid.

Få gjennomførte dobbeltkontroll ved generisk bytte, selv om dette er anbefalt i forskriften (3). Det er svært viktig at denne dobbeltkontrollen skjer mot en godkjent bytteliste.

I de tenkte eksemplene brukte 77 \% av sykepleierne informasjonskilder som ikke er egnet ved generisk bytte og ikke godkjent etter forskriften.

Vi vurderer at legemiddelverkets hjemmeside er lite egnet for sykepleiere til oppslag av byttbare preparater. Da er nettutgaven av Felleskatalogen enklere, der det eventuelt nederst i preparatomtalen vil være en lenke til «byttegruppe» med alle godkjent byttbare pakninger i samme styrke. Samme informasjon fremkommer også i Felleskatalogens app for smarttelefon som kom i ny versjon høsten 2017 (11), mens papirutgaven ikke har slike opplysninger.

\section{HYPPIGHET AV FEIL}

Sykepleierne svarte i median feil på to av seks tenkte eksempler. Dette sier imidlertid ikke noe om hvor ofte feil ved generisk bytte reelt skjer i sykehus, fordi de tenkte eksemplene var utvalgte problemstillinger. I hverdagen vil kanskje det vanligste være at preparater som sammenlignes har samme legemiddelform. Få svarte feil på det eneste eksemplet der preparatene var byttbare.

At over halvparten svarte feil på byttene Erymax kapsler/Abboticin ES tabletter og Tramagetic OD/Nobligan Retard, skyldes sannsynligvis at forskjellene er vanskelig å se ut fra preparatomtale og ATC-registeret. Det var mer uventet at $23 \%$ svarte feil på byttet Oxycodone kapsler til OxyContin depottabletter, ettersom forskjell i legemiddelform fremgår tydelig av navnet. Konsekvensen av å forveksle legemiddelform er sjelden alvorlig, men kan eksempelvis være farlig for sterke opioider. Zestoretic mite og Lisinopril har forskjellig innhold, men $21 \%$ svarte likevel feil. At enda flere (33\%) ville bytte Sinemet og Madopar, kan skyldes samme ATC-kode, selv om et av virkestoffene er forskjellige.

Generisk bytte er ikke nevnt som årsak til avvik i årsrapporten for 2017 fra Meldeordningen for uønskede hendelser i spesialisthelsetjenesten (12). Imidlertid er bare alvorlige hendelser meldepliktige, og det antas å være underrapportering (13). Forveksling av depottabletter og hurtigvirkende tabletter i sykehus er likevel en kjent problemstilling (14). Legemiddelverket har også laget informasjonsmateriell om forvekslingsfaren mellom tabletter og depottabletter (15).

\section{MULIGHETER FOR KVALITETSFORBEDRING}

Det blir feil å peke på sykepleierne som årsak til problemene ved generisk bytte. Her er det kvalitetssystemene som må forbedres. Bedre sikkerheten bør primært ivaretas med 
datatekniske løsninger. Lukket legemiddelsløyfe (closed loop medication) er i hovedsak basert på elektronisk kurve med beslutningsstøtte, elektronisk og manuelt identifiserbare legemidler og elektroniske kommunikasjons- og dokumentasjonssystemer. I Norge, Europa og USA er dette vurdert som et viktig systemforbedringstiltak for å redusere uønskede legemiddelhendelser. Ingen sykehus har så langt implementert dette i Norge, men noen sykehus arbeider for en slik løsning (16).

Når elektronisk kurve innføres, bør det uansett tilrettelegges for at byttbare preparater enkelt kan søkes opp og at bytter blir dokumentert automatisk. Apotekenes datasystemer har til sammenligning ivaretatt dette helt siden apotek begynte med generisk bytte i 2001.

Det aller viktigste, utenom tekniske løsninger, er forståelsen for at legemidler kun kan byttes med utgangspunkt i en godkjent bytteliste. Mange deltagere i studien svarte feil på eksempler selv om de brukte lokal bytteliste, så nødvendig opplæring må gis.

Foruten sykepleiere bør også leger være oppmerksomme på faren for feil ved generisk bytte og kontrollere dette i medisinkurvene. Sykehusapotekene kan involveres i

kvalitetsforbedring av generisk bytte på områder som undervisning, internkontroll og forbedring av rutiner. Kliniske farmasøyter bør i større grad enn nå brukes som en samarbeidspartner for å kvalitetssikre legemiddelbruken til den enkelte pasient.

Studien viser at merarbeid ved generisk bytte utgjør ca. 1,5\% av en normal arbeidsdag. Det høres lite ut, men det er drøyt 44 ooo årsverk sykepleiere i spesialisthelsetjenesten (17), hvilket gir 660 årsverk. Tallene er usikre, men betydelige ressurser kan åpenbart spares med mer effektive rutiner for generisk bytte.

\section{STYRKER OG BEGRENSNINGER}

Svarprosenten i studien er noe lav, men respondentene avspeiler en heterogen gruppe i alder og arbeidserfaring, og data er hentet fra flere helseforetak. Den enkelte sykehuspost bestemmer selv hvilke sykepleiere som skal registreres i Tønsys for bestilling av legemidler. Dette kan gi skjevheter i utvalget, og spesielt timelønnede sykepleiere og vikarer kan være underrepresentert. Ut fra resultatene fremstår sykepleiere som en svært homogen gruppe når det gjelder generisk bytte i sykehus, og mindre skjevheter i materialet antas å ikke ha stor betydning for resultatene. Studien bør derfor gi et godt bilde av situasjonen i sykehus med tilsvarende manuell istandgjøring av legemidler. Noen sykehus som ikke er inkludert i studien, har imidlertid helt andre rutiner, bl.a. med sentralisert dosepakking av legemidler til den enkelte pasient (16).

Resultatene viser at sykepleierne for det meste gjennomførte generisk bytte uten å involvere legen. Studien sier dessverre ikke noe om hvordan leger håndterer generisk bytte. Resultatene stemmer godt overens med en hovedoppgave fra 2009, der man fant mangelfulle rutiner, at bytter sjelden ble dokumentert og at bytter også forekom mellom ikke-byttbare preparater (18).

Det er sannsynlig at sykepleierne sjekker noe grundigere når det dreier seg om reelle pasienter i stedet for tenkte eksempler. De fleste hadde imidlertid tilgang på samme informasjonskilder som i en jobbsituasjon og ville neppe gjøre det på en prinsipielt forskjellig måte.

\section{Konklusjon}

Dagens praksis med generisk bytte i sykehus innebærer en unødvendig risiko for feilmedisinering. Studien understøtter dette og viser mangler i håndtering av generiske bytter. Sikre rutiner og gode kvalitetssystemer er et klart ledelsesansvar og må være på plass. De krav som forskriften setter til generisk bytte og bruk av byttelister er viktig basiskunnskap som bør inngå i sykepleiernes grunnutdanning. 
HOVEDBUDSKAP

$57 \%$ av sykepleierne byttet daglig mellom generiske legemidler

$37 \%$ oppga at det i minst $80 \%$ av tilfellene ble dokumentert hvilket preparat det byttes til

I median to av seks svar var feil i tenkte eksempler på generisk bytte

$23 \%$ brukte godkjent bytteliste i de tenkte eksemplene

\section{LITTERATUR:}

1. Tall og fakta. Legemidler og helsevesen 2018. Oslo: Legemiddelindustrien, 2018.

https://www.lmi.no/wp-content/uploads/2018/04/Tall-og-fakta-2018-1.pdf(26.9.2018).

2. Tall fra divisjon legemidler. Sykehusinnkjøp. https://sykehusinnkjop.no/legemidler/ (26.9.2018).

3. Legemiddelhåndteringsforskriften med kommentarer. Rundskriv IS-7/2015. Oslo: Helsedirektoratet, 2015 .

https://helsedirektoratet.no/Lists/Publikasjoner/Attachments/942/Rundskriv\%2oLegemiddelhåndteri ngsforskriften\%2oIS-7\%202015.pdf (26.9.2018).

4. Hvordan kommer et legemiddel på byttelisten? Statens legemiddelverk.

https://legemiddelverket.no/offentlig-finansiering/generisk-bytte/hvordan-kommer-et-legemiddel-pabyttelisten (26.9.2018).

5. Structure and principles. WHO Collaborating Centre for Drug Statistics

Methodology. https://www.whocc.no/atc/structure_and_principles/ (26.9.2018).

6. Johansen R, Fosnes GS, Holm H et al. Generisk bytte av legemidler i sykehus. Tidsskr Nor Lægeforen 2007; 127: 1232 - 3. [PubMed]

7. Johansen R. Hvilke legemidler er byttbare? Sykepleien 2011; 99: 57 - 9. [CrossRef]

8. 2018. Questback. https://www.questback.com/no/ (26.9.2018).

9. Tønsys. https:/|tonsys.sahf.no/ebestilling/ (26.9.2018).

10. Systematic sampling. Research Metodology.

https://research-methodology.net/sampling-in-primary-data-collection/systematic-sampling/ (26.9.2018).

11. Nytt om legemidler nr.1/2018. Statens Legemiddelverk.

https://legemiddelverket.no/Documents/Bivirkninger\%20og\%2osikkerhet/Råd\%2otil\%2ohelsepersonel 1/NYL/2018/2018_NYL\%2Onr\%201_lavoppløslig.pdf(26.9.2018).

12. Årsrapport 2017. Meldeordningen for uønskede hendelser i spesialisthelsetjenesten. IS-2729. Oslo: Helsedirektoratet, 2018.

https://helsedirektoratet.no/Lists/Publikasjoner/Attachments/1446/Arsrapport2017_Meldeordningen. $\operatorname{pdf}(26.9 .2018)$.

13. Norges offentlige utredninger. Med åpne kort - Forebygging og oppfølging av alvorlige hendelser i helse- og omsorgstjenestene. NOU 2015:11.

https://www.regjeringen.no/no/dokumenter/nou-2015-11/id2459861/ (26.9.2018).

14. Stenberg-Nilsen H, Larsen BM. Metoprolol-preparater og mulighet for feilmedisinering ved innleggelse på sykehus. RELIS, 2008.

https://relis.no/Aktuelt/Arkiv/2008/Metoprololpreparater_og_mulighet_for_feilmedisinering_ved_i nnleggelse_pa_sykehus (26.9.2018).

15. Tablett eller depottablett? Råd til helsepersonell. Oslo: Statens legemiddelverk, 2016.

https://legemiddelverket.no/bivirkninger-og-sikkerhet/rad-til-helsepersonell/tablett-eller-depottablet $\mathrm{t}(26.9 .2018)$.

16. Meld. St. 28 (2014-2015). Legemiddelmeldingen - Riktig bruk - bedre helse.

https://www.regjeringen.no/no/dokumenter/meld.-st.-28-20142015/id2412810/sec1 (26.9.2018).

17. Nøkkeltall for helse- og omsorgsektoren. IS-2712 Oslo: Helsedirektoratet, 2017.

https://helsedirektoratet.no/Lists/Publikasjoner/Attachments/1430/Nokkeltall-for-helsesektoren-2016-I 
S-2712.pdf(26.9.2018).

18. Hopen HS. Generisk substitusjon av legemidler på sykehus. Masteroppgave. Oslo: Farmasøytisk institutt, Universitetet i Oslo, 2009. https://www.duo.uio.no/handle/10852/12270 (26.9.2018).

Publisert: 4. januar 2019. Tidsskr Nor Legeforen. DOI: 10.4045/tidsskr.17.0722

Mottatt 23.8.2017, første revisjon innsendt 13.4.2018, godkjent 22.10.2018.

(C) Tidsskrift for Den norske legeforening 2020. Lastet ned fra tidsskriftet.no 